\section{Cancer in the Azores: Initial results from a recently established population-based cancer registry}

\section{Câncer nos Açores: Primeiros resultados de um registro oncológico de base populacional recentemente criado}

\author{
Gonçalo F. Lacerda' \\ Paulo S. Pinheiro" \\ José M. Cabral"'I \\ Jorge G. Câmaralv \\ Vítor L. Rodrigues ${ }^{\mathrm{V}}$ \\ 'Registo Oncológico Regional dos Açores, Centro de Oncologia dos Açores, \\ Portugal \\ "School of Community Health Sciences, University of Nevada, Las Vegas, USA \\ "'LABAP - Laboratório de Anatomia Patológica, Lda., Ponta Delgada, Portugal \\ IvServiço de Hemato-Oncologia, Hospital da Horta, Portugal \\ VInstituto de Higiene e Medicina Social, Faculdade de Medicina de Coimbra, \\ Portugal
}

\section{Abstract}

Introduction: The Azores archipelago has long been the Portuguese region that presents the highest mortality rates for certain cancers. Lack of incidence data has prevented the evaluation of the actual burden of this disease in the Azorean population. Methods: Malignant tumours (ICD-O $5^{\text {th }}$ Digit /3) initially diagnosed between the January $1^{\text {st }} 2000$ and December $31^{\text {st }} 2002$ were retrieved from the database of the recently established population-based cancer registry. Crude, age-specific and age-standardized rates were calculated and confidence intervals were estimated using Poisson approximation. Relative risks of developing cancer in the Azores when compared to mainland Portugal have been represented by standardized ratios. Quality indicators, including Mortality:Incidence (M:I) ratios, were also assessed. Results: Overall, the data shows a high incidence rate for some malignant diseases, specifically in men. Compared to those living in mainland Portugal, both Azorean men (RR 1.412; 99\% CI 1.407-1.416) and women (1.127; 1.1251.129) presented a significantly higher risk of developing cancer, all sites combined. When compared with other cancer registries, a less favourable cancer survival pattern is reported in the Azores, as emphasized by higher M:I ratios for several cancer sites. Conclusions: A preliminary analysis of the results suggests the presence of some major risk factors in the Azorean population, namely tobacco smoking in men. Higher M:I ratios would also point to survival disparities between the Azores archipelago and the continent, which should be further studied.

Keywords: Cancer. Incidence. Mortality. Registration. Archipelago. Azores. 


\section{Resumo}

Introdução: $\mathrm{O}$ arquipélago dos Açores é a região Portuguesa a apresentar as mais elevadas taxas de mortalidade por câncer desde há alguns anos. A ausência de dados de incidência tem constituído um obstáculo ao conhecimento da distribuição da doença oncológica na população açoriana. Metodologia: Todos os tumores malignos (50 dígito da ICD-O: /3) diagnosticados pela primeira vez entre 1 de Janeiro de 2000 e 31 de Dezembro de 2002 foram retirados da base de dados do Registo Oncológico Regional dos Açores. Foram calculadas as taxas brutas, específicas por idade e padronizadas, e estimados os respectivos intervalos de confiança, bem como os riscos relativos de desenvolver câncer nos Açores, em relação a Portugal continental. Finalmente, foram estabelecidos alguns indicadores de qualidade do Registo, como a razão mortalidade:incidência. Resultados: Em termos globais, os resultados demonstram que alguns cânceres, sobretudo nos homens, apresentam taxas de incidência relativamente elevadas. Considerando todas as localizações, quer os homens (RR 1.412; 99\% IC 1.407-1.416) quer as mulheres açorianas (1.127; 1.125-1.129) apresentaram um risco significativamente maior de desenvolver câncer, quando comparados com Portugal continental. No que respeita à razão mortalidade:incidência, os resultados poderão eventualmente apontar para padrões de sobrevivência mais desfavoráveis nos Açores relativamente a outras regiões europeias, incluindo o continente. Conclusão: Uma análise preliminar dos resultados aponta para a existência de fatores de risco, como o consumo de tabaco, a contribuir para a elevada incidência de câncer do pulmão nos homens açorianos. Eventuais disparidades na sobrevivência por câncer entre os Açores e o continente deverão também ser futuramente estudadas.

Palavras-chave: Câncer. Incidência. Mortalidade. Registo. Arquipélago. Açores.

\section{Introduction}

In 2008, an estimated 3.2 million cancer cases have been diagnosed in forty European countries and an estimated 1.7 million deaths have also been attributed to cancer ${ }^{1}$.

The sharp increase in life expectancy, together with the more widespread adoption of western lifestyles and practices, including smoking, are largely responsible for the increased incidence of cancer in many parts of the world. Breast, prostate, lung, colon and rectum cancers are the sites most strongly affected by these phenomena ${ }^{2}$.

Cancer incidence, prevalence, mortality and survival are considered to be the four major health indicators contributing to cancer control and prevention ${ }^{3}$.

Population-based cancer registries are responsible for collecting cancer data on a patient-by-patient basis. Such data includes patient identification, tumour characteristics and treatment undertaken, as well as follow-up, in order to assess cancer burden, preventive measures, patient and healthcare, and research developments in terms of assessing causes ${ }^{4-7}$

The Azores archipelago has long been the Portuguese region representing the highest mortality rates for certain cancers, especially those related to tobacco consumption ${ }^{8}$. A lack of incidence data in several reports and studies ${ }^{9-12}$ has prevented the evaluation of the real burden of the disease among the Azorean population.

A cancer registry was created as of 15 July 1993 by Ordinance \# 36/93. However, the Azores Oncological Centre has only recently published the initial results on cancer incidence in the Azores complemented by official mortality statistics for the 2000-2002 period $^{13}$. In this study, data has been up-dated for this same period (2000-2002).

We aim to present the first cancer incidence data in the Azores as well as standardized data quality indicators, and compare both data to other cancer registries. 


\section{Methods}

\section{Population and specified cancer registry parameters}

The Azores archipelago is an autonomous Portuguese region which comprises nine volcanic islands located in the North Atlantic within latitudes $36^{\circ}$ and $43^{\circ} \mathrm{N}$ and longitudes $25^{\circ}$ and $31^{\circ} \mathrm{W}$ respectively. The islands are divided into three groups: the Western (Flores and Corvo), Central (Terceira, Faial, Pico, São Jorge and Graciosa) and Eastern (São Miguel and Santa Maria) groups. In the 2001 Census the population was 241,763 inhabitants $(119,486$ men and 122,277 women) ${ }^{14}$. The Region is divided into 19 administrative boroughs.

The Azorean population lifestyle has changed dramatically in the past 35 years, with substantial socio-economic development after Portugal joined the former European Economic Community in 1986. Even so, according to Article 299 (2) of the European Community (EC) Treaty, the Azores are still classified as an 'Outermost Region'. Rural areas cover $99.6 \%$ of the archipelago and the entire territory is classified as a 'Less-Favoured Area', that is, an area with specific disadvantages.

There are three important health institutions, namely hospitals, in the Autonomous Region. They are situated on the islands of São Miguel, Terceira and Faial. There are also 16 health centres and one oncological centre (AOC). The latter takes responsibility for both the Azores Cancer Registry and cancer screening programmes. Breast and cervical cancer screening services were launched in November 2008 and February 2010, respectively.

\section{Data collection and sources of cases}

Data collection is both passive and active. The Registry covers the entire 2,346 $\mathrm{Km}^{2}$ of the archipelago. The main sources of cancer incidence data are the three regional public hospitals, previously mentioned, a number of private pathology laboratories located both in the archipelago and on the Portuguese mainland and the three regional population-based cancer registries located on the mainland. The Registry receives information in the electronic format from the regional public hospital units, namely the Pathological and Onco-Haematological services. Private laboratories routinely forward their information as pathology reports. The three regional Portuguese cancer registries contribute with information on Azorean oncological patients who are diagnosed and treated outside of the Azores archipelago.

Death certificates specifically mentioning cancer are also collected by the Registry. 'After all trace-back manoeuvres have been completed ${ }^{\prime 15}$ a residuum of this information is registered as DCOs.

Based on the information produced both by the Hospital's Information System and by death certificates mentioning cancer, Registry personnel actively look for patients' clinical data in hospitals and health centres.

As all three hospitals mentioned had their cancer diagnosis and treatment units fully computerized before 2000, an active surveillance of their databases was performed in order to identify all possible prevalent cases that first came to light in the form of incidence. This has reduced substantially those cases for which a local/ regional recurrence or a metastasis was diagnosed during the $2000-2002$ period.

\section{Registry techniques}

At the Registry, tumours cases are collected and classified routinely according to the International Classification of Diseases for Oncology (ICD-O $)^{16}$. In this study the International Classification of Diseases (ICD $)^{17}$ criteria was utilised and presented in a table. Only malignant tumours (ICD-O $5^{\text {th }}$ Digit/3) initially diagnosed between January $1^{\text {st }} 2000$ and December $31^{\text {st }} 2002$ were included in the statistical analysis.

Multiple primary tumours were classified according to international rules ${ }^{18}$. To carry out conversion from ICD-O to ICD and to check for variable inconsistencies, 
the IARCcrgTools version 2.04 was used ${ }^{19}$. Double entries were identified and excluded by means of the same first name, surname, date-of-birth and birthplace, as well as hospital registry number.

\section{Data quality indices}

Data quality indices evaluated in this study include:

- Comparability, specifically related to standardized techniques for classification of tumours adopted by the Registry. This was employed so our results could be directly and easily compared to other cancer registries (see 3 - Registry techniques). According to Bray and Parkin ${ }^{20}$ this quality indicator includes (1) international standards for classification and coding of neoplasms, (2) incidence date, (3) multiple primaries, and (4) incidental diagnosis. For the purpose of this study only the first two were considered.

- Validity, with specific reference to the 'proportion of cases in a dataset with a given characteristic which truly have the attribute ${ }^{20}$. In this study, only histological verification and death-certificate-only cases were evaluated;

- Completeness, in this instance refers to the 'extent to which all incident cancers occurring in the population are included in the registry database ${ }^{21}$. Completeness has been evaluated using (1) mortality:incidence ratios, (2) proportion of microscopically verified cases, and (3) proportion of death-certificate-only cases. The two latter are also included in 'validity'.

Mortality data (2000-2002) were obtained from National Health Statistics.

Data quality Indices were compared to those for southern Portugal ${ }^{22}$, Navarra ${ }^{23}$ and $\operatorname{Tarn}^{24}$, all included in the Cancer Incidence in Five Continents Vol. IX ${ }^{25}$.

\section{Statistical analysis}

Crude (all-ages) and age-specific rates were calculated using the population at risk for the 2000-2002 period obtained from 'Statistics Portugal'. ${ }^{26}$ Mean annual age-standardized rates (ASR) were computed by the direct method, based on European and World standard population numbers. Confidence intervals were estimated using Poisson approximation ${ }^{27}$. Cumulative risks were assessed for the 0 to 64 and 74 year-old parameters.

Relative risks for developing cancer in the Azores when compared to mainland Portugal have been represented by standardized rate ratios ${ }^{27}$.

\section{Results}

Incidence and relative proportions; crude and standardized rates and cumulative risks are presented in Table 1 , according to cancer site (ICD-10) and sex. A total of 2,515 new cases, excluding non-melanoma skin cancer, were diagnosed: 1,487 in men and 1,028 in women. The most common cancers in men were prostate cancer (88.7 cases per 100,000 inhabitants), lung cancer (84.8), oral cavity cancer (34.0), colorectal cancer (33.5) and stomach cancer (30.1). The most common cancers in women were breast cancer (82.4 cases per 100,000 inhabitants), colorectal cancer (35.2), corpus uteri cancer (18.3), stomach cancer (13.6) and thyroid cancer (13.3). In the absence of other causes of death, a male in the Azores archipelago had an estimated $31.5 \%$ risk of developing cancer before the age of 75 , while in women the risk was $19.3 \%$.

Tables 2 and 3 show indices of quality for cancer data from four different population-based cancer registries, including the Azores. In the Azores, the proportion of microscopically verified cases ranked above $80 \%$ in both men (84.1) and women (86.0), while the proportion of death-certificate-only cases ranked below $10 \%$. If we exclude MV and DCO cases, the remainder are cases based on clinical, imaging and biomarker diagnosis. For all cancer sites, Mortality:Incidence (M:I) ratios were higher in men (65.9\%) compared to women (52.7\%). In comparison with other cancer 


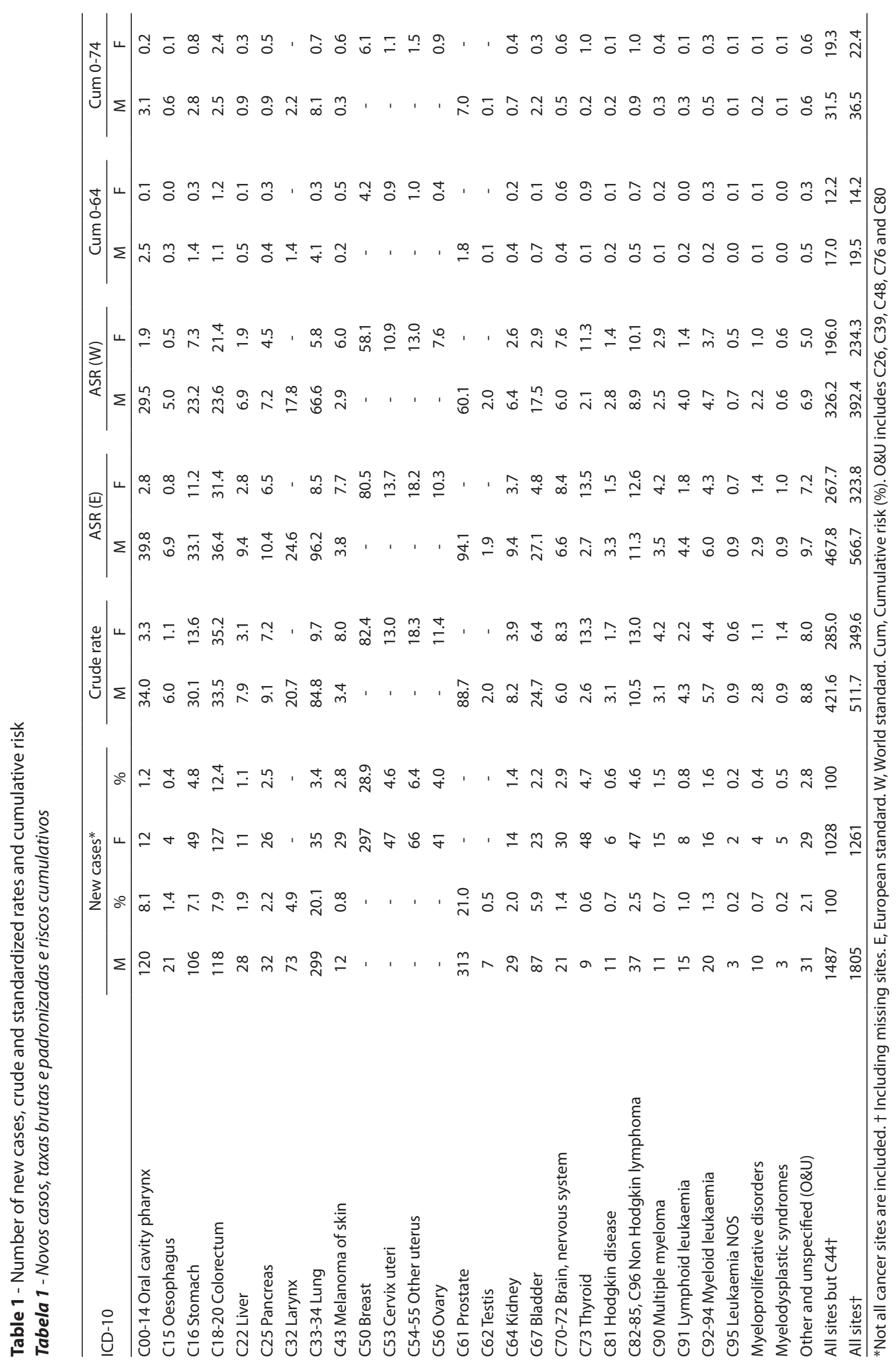




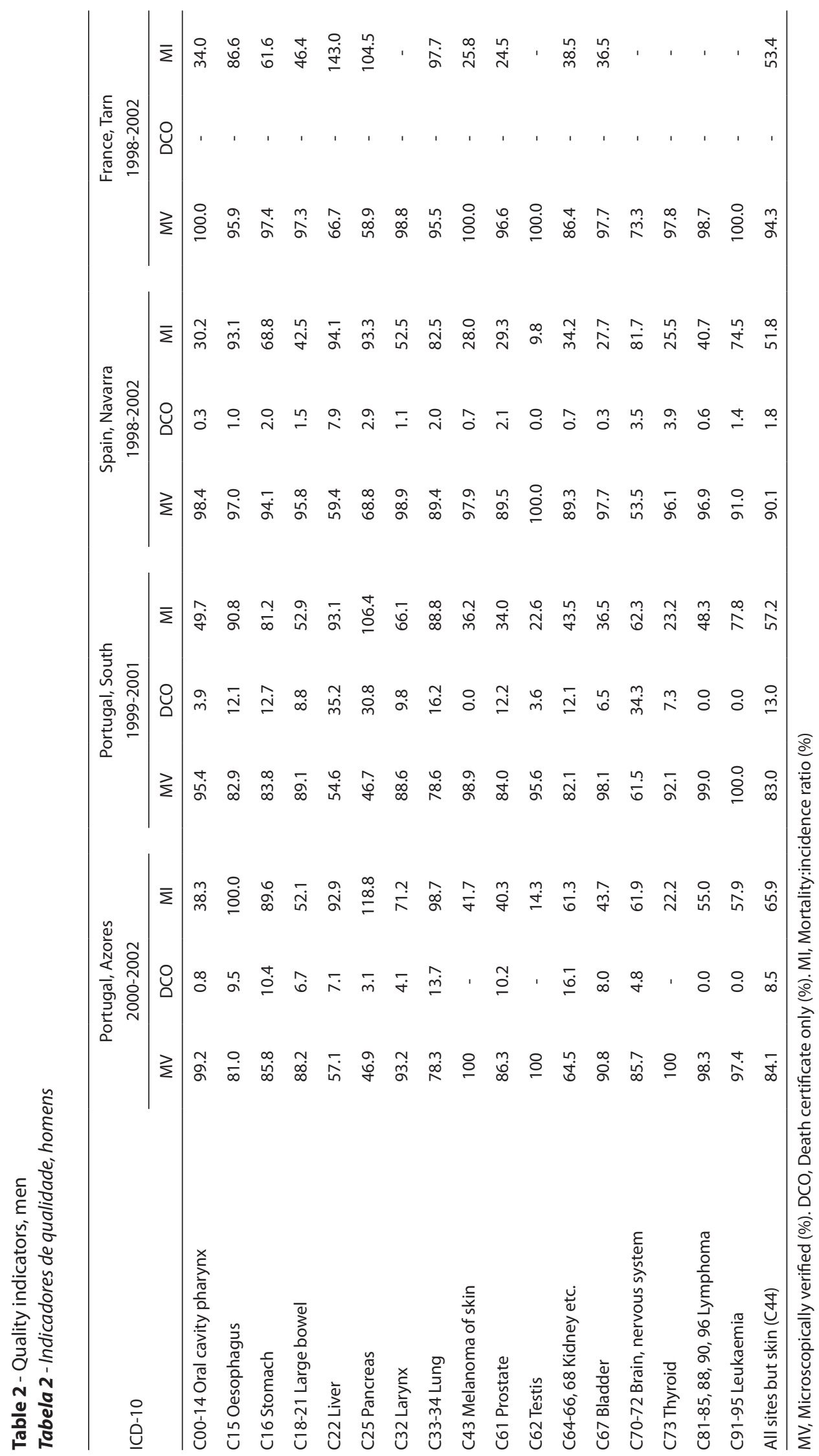




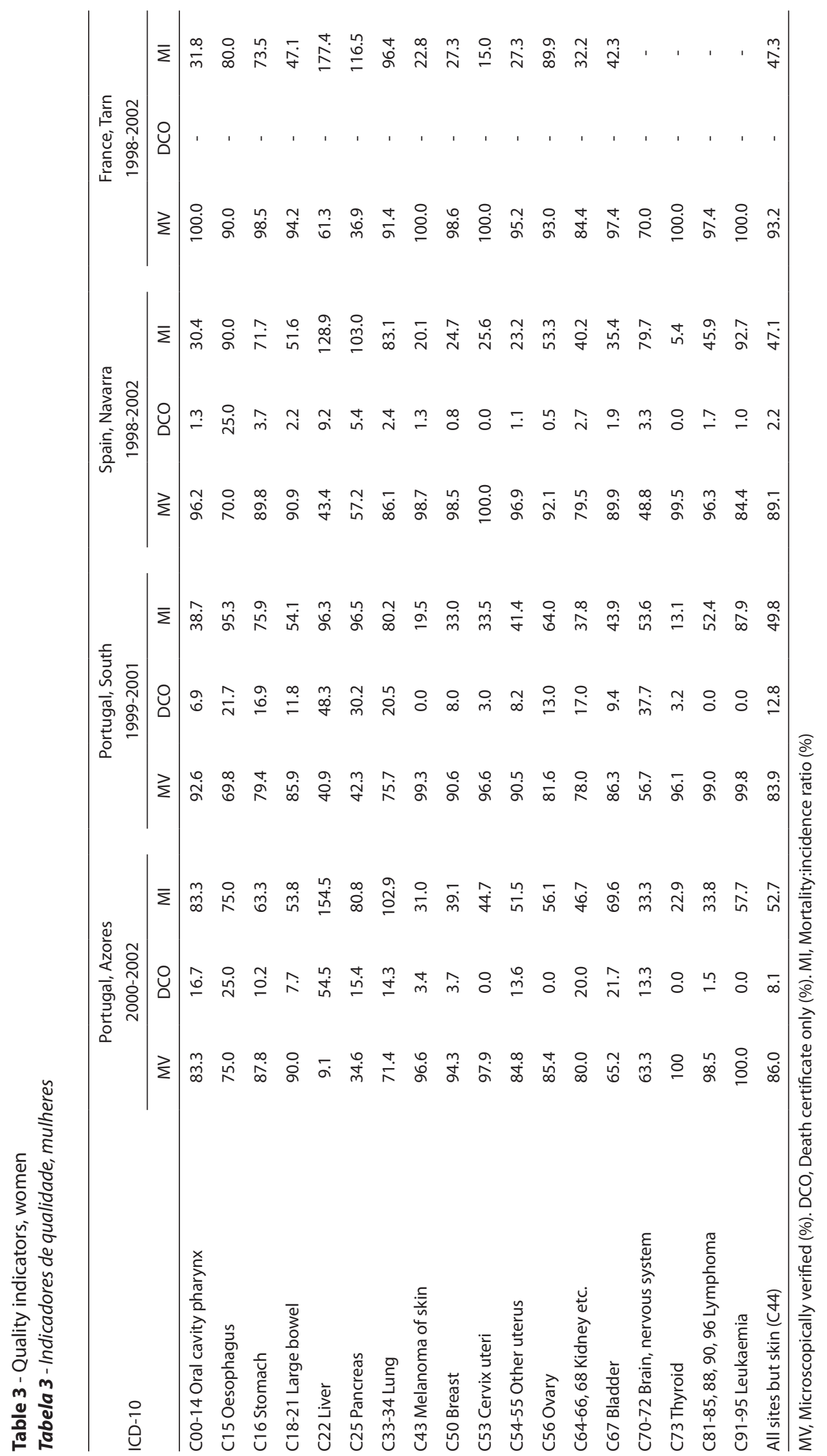


registries, the Azores presented the highest values of M:I ratios among numerous cancer sites.

Table 4 shows age-standardized rates for major cancer sites in men and women, as well as their $95 \%$ confidence intervals. It also shows relative risk levels, represented by standardized rate ratio (SRR) for the Azores and the Portuguese mainland. ${ }^{11}$ The SRRs were significantly higher in Azorean men for stomach (RR 1.132; 99\% CI 1.107-1.157), liver $(2.226$; 1.421-3.486) pancreas (2.323; 1.487-3.627), lung (2.643; 2.535-2.755), prostate (1.351; 1.329-1.373), bladder (1.190 1.139-1.244), leukaemia (1.492; 1.239-1.796) and all sites combined (1.412; 1.407-1.416). Only colorectal cancer presented a significantly lower relative risk in Azorean men (0.656; 0.577-0.745). In women SRRs were significantly higher in corpus uteri (1.543; $1.336-1.782)$, brain (1.900; $1.366-2.644)$, thyroid (1.378; 1.214-1.564), lymphoma (1.497; 1.340-1.672) and all sites combined (1.127; 1.125-1.129).

\section{Discussion}

This is the first time that cancer data from the Azores, a peripheral part of Europe, was analysed and described.

Data emerging from recently established cancer registries should be viewed with caution since the period of time is insufficient to identify all prevalent cases, not least as some of them will probably have been registered as incident cases. However, taking into account the data presented here and from well-established cancer registries (Tables 2 and 3 ) it is clear that our effort to reduce prevalent cases to obtain accurate incidence rates has been worthwhile.

Lip, oral cavity (including pharynx), oesophagus, stomach, liver, larynx, lung and bladder cancers were far more common in men than in women. Alcohol consumption, acting in synergy with smoking, could in part explain the different patterns of cancer incidence between sexes, as men are more likely to be addicted to ethanol and nicotine ${ }^{28-31}$. It has been estimated that in the Azores the number of men who smoke is more than twice the number of women, $46.6 \%$ and $20.9 \%$, respectively ${ }^{32}$.

Prostate cancer, which represents $21.0 \%$ of all cancers in males, and lung cancer (20.1\%) were by far the most frequent sites. Azorean men had a 35\% increased risk of prostate cancer compared to other Portuguese men (Table 4). Prostate cancer incidence data around the globe is highly influenced by PSA testing, as a significant proportion of cases identified through such testing will never become symptomatic ${ }^{33-35}$. Azorean men were also 2.64 times more likely to develop lung cancer compared to their mainland compatriots (Table 4). In a national survey concerning risk factors for lung cancer, a lower proportion of males who had never smoked were detected in the Azores (42\%) when compared to those living on the mainland $(46 \%)^{36}$. Of those who were current smokers, $22 \%$ of the Azorean men usually smoked less than 21 cigarettes per day, compared to $19 \%$ of their mainland compatriots. Likewise, there was a significant difference in the number of individuals smoking more than 21 cigarettes per day (12\%), compared to $6 \%$ on the mainland. This data covers the 2005/06 period, which should remind us that the scenario could have been quite different 20-30 years ago. In Portugal, legal restrictions on smoking in public places have been implemented as of January 1, 2008. Over the coming decades, this political decision will probably decrease the risk for developing some forms of cancer, such as lung, larynx and bladder cancer, mainly in men.

In women, breast cancer ranked first in incidence and mortality from cancer. A total of 297 new cases $(28.9 \%$ of all female cancers) were diagnosed in 2000-2002 and 116 women died from it in the same period. There were no significant statistical differences between the Azorean women and those from mainland Portugal (Table $4)$. Worth noting is the $54 \%$ increased risk (1.543; 1.336-1.782) in corpus uteri cancer in Azorean women, compared to other Portuguese women. 


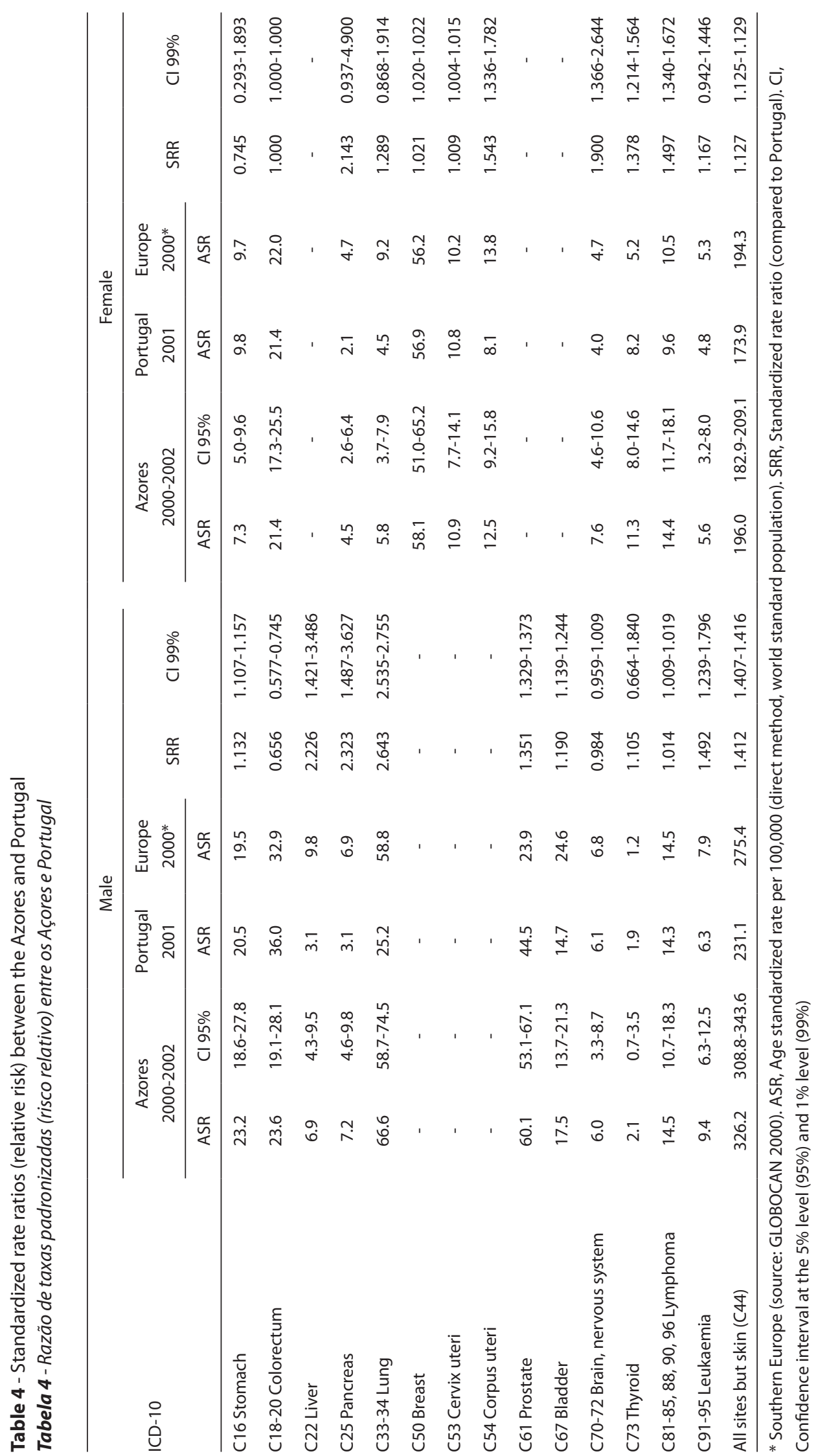


Colorectal cancer is much more frequent in mainland Portugal for both sexes. In the Azores it ranks fourth after breast cancer in women, and prostate and lung cancer in men while on the mainland it ranks first $^{11-12}$. Azorean men were $35 \%$ less likely to develop colorectal cancer, compared to other Portuguese men (99\% CI 0.577-0.745). In Azorean women, evidence for a similar reduced risk was not observed $(1,000 ; 1,000$ $1,000)$. Colorectal cancer is a cancer which targets those who can be classified as middle or old-aged, and its risk is higher in more developed (industrialised) countries ${ }^{2}$. This may partly explain the difference between Azorean rates and those of the mainland since the entire Archipelago is classified as a 'Less-Favoured Area'.

The risk of being diagnosed with melanoma-type skin cancer follows the international pattern, i.e. the risk in women is roughly two times greater than in men $^{2}$. Crude rates were 8.0 and 3.4 per 100,000 , respectively.

With respect to M:I ratios, results point towards different cancer fatality and survival patterns among Azorean men and women. Across several cancer sites, men were more likely to die than women. Take, for example, statistics for skin melanoma, where the M:I ratio highlighted a better survival pattern in women (M:I 31.0\%) compared to men $(41.7 \%)$, despite the increased risk among the former. This fact is probably related to women seeking more regularly medical advice $^{37}$. In women, cervical cancer presented the lowest M:I ratio (44.7\%), followed by corpus uteri $(51.5 \%)$ and finally by ovary cancer (56.1\%). These figures could also partly reflect different cancer survival patterns for female specific cancers.

The Azores presented higher M:I ratios in several cancer sites, particularly in men, when compared to other cancer registries (Tables 2 and 3). A possible and worrisome interpretation of this fact points to lower cancer survival patterns in the Azores, which in turn could be related to difficulties in access to health care services, low economic and educational levels (only $7.3 \%$ of people have high level schooling) or even the inadequate number of health professionals. However, since M:I interpretation is ultimately related to how death certificates are being collected and classified, and that this process was found to be inaccurate, especially in Portugal ${ }^{15,38,39}$, survival studies are needed to assess the real impact of cancer in life expectancy. A first step towards this goal has been taken through participation of the Azores in the $5^{\text {th }}$ edition of the EUROCARE project.

From analysis of the data concerning M:I ratios, lack of completeness for some rapidly fatal malignancies was also noted. These include oesophagus and pancreas cancer in men, and liver and lung cancer in women.

With respect to validity, liver, pancreas, lung and kidney cancer in men, and oesophagus, liver, pancreas, lung and brain cancer in women, are the sites which require further attention in the future since a sizeable proportion of them received a less accurate diagnosis, and lack microscopic verification. Even so, for all sites combined, the results for microscopically verified cases indicate a generous allocation of pathology laboratories serving the Azorean population. They also contribute to a positive outcome in terms of the validity of the Registry data since the conclusion thus drawn tells us that the majority of cases being registered are truly invasive cancers.

\section{Conclusions}

The results outlined in this study highlight a very satisfactory level of accuracy and completeness in the Azores Registry, taking into account it is a new cancer registry. Comparable data between our Registry and that from other well established cancer registries were also achieved due to the adoption of standardized classifying techniques. In the absence of other explanations, the analysis of the results suggests the presence of some major risk factors, namely tobacco smoking in men. However, we cannot exclude other minor risk factors like long-term exposure to low doses of toxic 
gases (e.g. radon) derived from volcanic activity $^{40-42}$ or the possibility, yet unexplained, of high genetic susceptibility to some forms of cancers present in the Azorean population. Therefore, epidemiological studies are needed to assess the impact these other risk factors may have.

A cancer registry established in a small archipelago has some pros and cons when compared to mainland cancer registries. First of all, a small but significant proportion of Azorean cancer patients require referring to mainland hospitals, which increases the probability of the cancer registry not being able to trace cancer cases properly. In this situation, comprehensive data collection can be improved by having access to patients' transfer files when treatment shifts from the Azores to the mainland. This is something that has already been initiated by the Cancer Registry. Nevertheless, due to such a small and confined population, it is easier to fulfil completeness requirements and to define place of residence. Furthermore, as the majority of cancer diagnosis is performed in the three regional hospitals, tracking cancer cases will mainly require unconditional access to clinical information within all departments, as well as patient administrative data. Finally, the small population base of the Azores leads to some difficulties in interpreting cancer incidence rates, especially for rarer cancers. As such, annual cancer incidence statistics should be grouped and analysed every three years.

The aim of any population-based cancer registry is to provide unbiased information concerning cancer incidence, prevalence and survival within a given population. Mortality data is generally included in the reports of cancer registries. However, the source of the data is not the Cancer Registry. Though, one can note that according to Parkin et al. ${ }^{43}$, this different sourcing of mortality data is a good example of independent case ascertainment. To help fulfil these requirements, in 2008 and 2009, this Registry became a member of the European Network of Cancer Registries and of the International Association of Cancer Registries, respectively. To make our data available at an international level, the Registry has also recently participated in two major European projects, the EUROCIM-2 and the EUROCARE-5, and has already submitted its data to the next edition of the Cancer Incidence in Five Continents series, whose volume will cover the period 2003-200744.

For those who are willing to pursue such an important task, one should say that a population-based cancer registry in the Azores is not a luxury but a necessity ${ }^{45}$, for is the only way to assess cancer burden and to establish realistic cancer control and preventative measures in our Region.

\section{Conflict of interest statement: None} declared.

\section{References}

1. Ferlay J, Parkin DM, Steliarova-Foucher E. Estimates of cancer incidence and mortality in Europe in 2008. Eur J Cancer 2010;46:765-81.

2. Boyle P, Levin B (ed). World Cancer Report 2008. Lyon: International Agency for Research on Cancer; 2008.

3. dos Santos Silva I. Cancer Epidemiology: Principles and Methods. Lyon: International Agency for Research on Cancer; 1999. p. 385-403.

4. Jensen OM and Whelan S. Planning a cancer registry. In: OM Jensen, DM Parkin, R Maclennan, CS Muir, RG Skeet (ed). Cancer registration. Principles and methods (IARC Sci Publ No. 95). Lyon: International Agency for Research on Cancer; 1991. p. 22-8.
5. Micheli A, Coebergh JW, Mugno E, et al. European health systems and cancer care. Ann Oncol 2003; 14(S5): 41-60.

6. Parkin DM. The role of cancer registries in cancer control. Int J Clin Oncol 2008; 13: 102-11.

7. Engholm G, Ferlay J, Christensen N et al. NORDCAN - a Nordic tool for cancer information, planning, quality control and research. Acta Oncol 2010; 49: 725-36.

8. DGS. Risco de Morrer em Portugal. Lisboa: DirecçãoGeral da Saúde; 1998-2005.

9. Pinheiro PS, Tyczynski JE, Bray F et al. Cancer in Portugal. (IARC Technical Publication No. 38). Lyon: International Agency for Research on Cancer; 2002. 
10. Pinheiro PS, Tyczynski JE, Bray F et al. Cancer incidence and mortality in Portugal. Eur J Cancer 2003; 39: 250720.

11. IPO. Registo Oncológico Nacional 2001. Porto: Instituto Português de Oncologia de Francisco Gentil; 2008.

12. IPO. Registo Oncológico Nacional 2005. Coimbra: Instituto Português de Oncologia de Francisco Gentil; 2009.

13. COA. Incidência do Cancro na Região Autónoma dos Açores 2000-2002. Angra do Heroísmo: Centro de Oncologia dos Açores; 2008.

14. INE. Principais Resultados Definitivos dos Censos 1991 e 2001. Lisboa: Instituto Nacional de Estatística; 2003. p. 51-66.

15. Parkin DM, Plummer M. Comparability and quality of data. In: DM Parkin, SL Whelan, J Ferlay, et al. (ed). Cancer incidence in five continents - Volume VIII. (IARC Sci Publ No. 155). Lyon: International Agency for Research on Cancer and International Association of Cancer Registries; 2002. p. 68.

16. Fritz A, Percy C, Jack A et al. (ed). International Classification of Diseases for Oncology: ICD-O. Third edition. Geneva: World Health Organization; 2000.

17. WHO. International Statistical Classification of Diseases and Related Health Problems: ICD. Tenth revision. Geneva: World Health Organization; 1992.

18. Tyczynski JE, Démaret E, Parkin DM (ed). Standards and Guidelines for Cancer Registration in Europe. The ENCR Recommendations, Vol. I. (IARC Technical Publication No. 40). Lyon: International Agency for Research on Cancer; 2003. p. 4-10.

19. Ferlay J, Burkhard C, Whelan S, Parkin DM. Check and Conversion Programs for Cancer Registries (IARC Technical Report No. 42). Lyon: International Agency for Research on Cancer; 2005.

20. Bray F, Parkin DM. Evaluation of data quality in the cancer registry: Principles and methods. Part I: Comparability, validity and timeliness. Eur J Cancer 2009; 45: 747-55.

21. Parkin DM, Bray F. Evaluation of data quality in the cancer registry: Principles and methods. Part II: Completeness. Eur J Cancer 2009; 45: 756-64.

22. Miranda A, Fonseca R, Pereira A et al. Portugal, South Regional (1999-2001). In: MP Curado, B Edwards, HR Shin et al. Cancer incidence in five continents. (IARC Sci Publ No. 160, vol. IX). Lyon: International Agency for Research on Cancer; 2007.

23. Ardanaz E, Barricarte A, Rada ME et al. Spain, Navarra (1998-2002). In: MP Curado, B Edwards, HR Shin et al. Cancer incidence in five continents. (IARC Sci Publ No. 160 , vol. IX). Lyon: International Agency for Research on Cancer; 2007.
24. Grosclaude P, Sauvage M, Daubisse-Marliac, L et al. France, Tarn (1998-2002). In: MP Curado, B Edwards, HR Shin et al. Cancer incidence in five continents. (IARC Sci Publ No. 160, vol. IX). Lyon: International Agency for Research on Cancer; 2007.

25. Curado MP, Edwards B, Shin HR, et al. Cancer incidence in five continents. (IARC Sci Publ No. 160, vol. IX). Lyon: International Agency for Research on Cancer; 2007.

26. INE. Estimativas Anuais da População Residente. Lisboa: Instituto Nacional de Estatística, http://www.ine.pt [accessed 15.05.2010].

27. Boyle P, Parkin DM. Statistical methods for registries. In: OM Jensen, DM Parkin, R Maclennan, CS Muir, RG Skeet (ed). Cancer registration. Principles and methods (IARC Sci Publ No. 95). Lyon: International Agency for Research on Cancer; 1991. p. 126-58.

28. Brown LM. Epidemiology of alcohol-associated cancers. Alcohol 2005; 35: 161-8.

29. Boffetta P, Hashibe M. Alcohol and cancer. Lancet Oncol 2006; 7: 149-56.

30. Mackay J, Jemal A, Lee NC and Parkin DM O. The Cancer Atlas. Atlanta: American Cancer Society; 2006. p. 30-1, 44-5.

31. Mackay J, Eriksen M, Shafey O. The Tobacco Atlas. Atlanta: American Cancer Society; 2006. p. 22-5.

32. Peixoto A. Dependências e outras violências. Perspectiva Taxológica. Ponta Delgada: Polícia de Segurança Pública; 2005. p. 167-79.

33. Andriole GL, Grubb RL, Buys SS et al. Mortality Results from a Randomized Prostate-Cancer Screening Trial. $N$ Engl J Med 2009; 360: 1310-9.

34. Brawley OW. Prostate Cancer Screening; Is This a Teachable Moment? J Natl Cancer Inst 2009; 101: 1-3.

35. Schröder FH, Hugosson J, Roobol MJ et al. Screening and Prostate-Cancer Mortality in a Randomized European Study. N Engl J Med 2009; 360: 1320-8.

36. INE/INSA. Inquérito Nacional de Saúde 2005/2006. Lisboa: Instituto Nacional de Estatística/Instituto Nacional de Saúde Doutor Ricardo Jorge; 2009.

37. Black RJ, Bray F, Ferlay J, Parkin DM. Cancer Incidence and Mortality in the European Union: Cancer Registry Data and Estimates of National Incidence for 1990. Eur J Cancer 1997; 33: 1075-107.

38. Amado J, Matos E, Calheiros JM et al. Qualidade dos certificados de óbito em Vila Nova de Gaia. Saúde em Números 1990; 3: 22-4.

39. Mathers CD, Ma Fat D, Inoue M, Rao C, Lopez A. Counting the dead and what they died from: an assessment of the global status of cause of death data. Bull World Health Org 2005; 83: 171-7. 
40. Pellegriti G, De Vathaire F, Scollo C et al. Papillary Thyroid Cancer Incidence in the Volcanic Area of Sicily. J Natl Cancer Inst 2009; 101: 1575-83.

41. Field R, Steck D, Smith B et al. The Iowa radon lung cancer study - phase I: residential radon gas exposure and lung cancer. Sci Total Environ 2001; 272: 67-72.

42. Amaral A, Rodrigues V, Oliveira J et al. Chronic exposure to volcanic environments and cancer incidence in the Azores, Portugal. Sci Total Environ 2006; 367: 123-8.

43. Parkin DM, Chen VW, Ferlay J, Galceran J, Storm HH, Whelan SL. Comparability and Quality Control in Cancer Registration (IARC Technical Report No. 19). Lyon, International Agency for Research on Cancer; 1994. p. 14-41.
44. IACR. Newsletter No. 36. Lyon, International Association of Cancer Registries; July 2010.

45. Valsecchi MG, Steliarova-Foucher E. Cancer registration in developing countries: luxury or necessity? Lancet Oncol 2008; 9: 159-67.

Recebido em: 11/01/2011

Versão final apresentada em: 13/02/2012

Aprovado em: 16/02/2012 